Jurnal Sains Riset (JSR)

ISSN 2088-0952

\title{
PENGARUH KOMUNIKASI TERHADAP KEPUASAN KERJA PEGAWAI PADA DINAS PERTANIAN DAN PETERNAKAN KABUPATEN PIDIE
}

\author{
Herizal $^{1}$, Muhammmad Nur ${ }^{2}$ \\ ${ }^{1,2}$ Fakultas Ekonomi Universitas Jabal Ghafur \\ ${ }^{1}$ herizal_aprc@yahoo.co.id
}

\begin{abstract}
ABSTRAK
Lokasi penelitian ini dilakukan di Dinas Pertanian dan Peternakan Kabupaten Pidie. Tujuan penelitian ini adalah Untuk mengetahui pengaruh komunikasi internal dan eksternal terhadap kepuasan kerja pegawai pada Dinas Pertanian dan Peternakan Kabupaten Pidie. Jumlah responden yang dijadikan sampel mencapai 35 orang responden, yaitu pegawai dan para petani. Peralatan analisis yang digunakan adalah analisis regresi linier berganda, dengan hasil sebagai berikut : $\mathrm{Y}=$ $1,853+0,942 X_{1}+0,468 X_{2}$. Dari persamaan di atas, dapat diketahui nilai dari masing-masing koefisien, yaitu : nilai konstanta $(\alpha)$ sebesar 1,853, variabel komunikasi internal $\left(\mathrm{X}_{1}\right)$ sebesar 0,942, variabel komunikasi eksternal $\left(\mathrm{X}_{2}\right)$ sebesar 0,468. Variabel yang paling dominan berpengaruh adalah variabel komunikasi internal $\left(\mathrm{X}_{1}\right)$, yaitu memperoleh nilai sebesar 0,942. Besarnya pengaruh antara variabel komunikasi internal $\left(\mathrm{X}_{1}\right)$, dan komunikasi eksternal $\left(\mathrm{X}_{2}\right)$ secara bersama-sama berpengaruh secara signifikan terhadap kepuasan kerja pegawai pada Dinas Pertanian dan Peternakan Kabupaten Pidie 95,9\%. Hanya sebesar 4,1\% yang dipengaruhi oleh variabel lain yang tidak diteliti dalam penelitian. Secara simultan di peroleh $F_{\text {hitung }} 372,427>F_{\text {tabel }}$ 3,2945. Dengan demikian, variabel komunikasi internal $\left(\mathrm{X}_{1}\right)$, dan komunikasi eksternal $\left(\mathrm{X}_{2}\right)$, secara bersama-sama berpengaruh secara signifikan terhadap kepuasan kerja pegawai pada pada Dinas Pertanian dan Peternakan Kabupaten Pidie.Secara parsial variabel komunikasi internal $\left(\mathrm{X}_{1}\right)$, diperoleh $t_{\text {hitung }} 9,411>t_{\text {tabel }} 2,0369$, variabel komunikasi eksternal $\left(X_{2}\right)$, diperoleh $t_{\text {hitung }} 4,508>$ $\mathrm{t}_{\text {tabel }}$ 2,0369. Jadi dapat disimpulkan bahwa variabel komunikasi internal $\left(\mathrm{X}_{1}\right)$ dan variabel komunikasi eksternal $\left(\mathrm{X}_{2}\right)$, memberikan pengaruh yang signifikan terhadap kepuasan kerja pegawai pada Dinas Pertanian dan Peternakan Kabupaten Pidie. Dari hasil penelitian dapat disimpulkan bahwa variabel komunikasi internal $\left(\mathrm{X}_{1}\right)$, dan variabel komunikasi eksternal $\left(\mathrm{X}_{2}\right)$ berpengaruh secara signifikan terhadap kepuasan kerja pegawai pada Dinas Pertanian dan Peternakan Kabupaten Pidie.
\end{abstract}

Kata Kunci : Komunikasi Internal, Komunikasi Eksternal dan Kepuasan Kerja

\section{Pendahuluan}

\section{Latar Belakang Penelitian}

Dinas Pertanian dan Peternakan Kabupaten Pidie merupakan Dinas yang melaksanakan tugas Pemerintah Kabupaten Pidie yang berorientasi memberikan pelayanan teknis bidang pertanian dan peternakan kepada masyarakat di Kabupaten Pidie. Dinas Pertanian dan Peternakan mempunyai visi untuk terwujudnya masyarakat tani yang tangguh dan mandiri untuk meningkatkan kesejahteraan rakyat di Kabupaten Pidie.

Sebagai organisasi pemerintah dibentuk untuk berorientasi kepada perbaikan pelayanan pelanggan atau masyarakat, pemenuhan permintaan pasar dan meningkatnya kinerja organisasi. Peningkatan kinerja pegawai dapat diperoleh dari sumber daya manusia yang kompeten 
yang memiliki kepuasan yang tinggi. Salah satu upaya dalam mempertahankan pegawainya adalah dengan tetap memperhatikan kepuasan kerja.

Kepuasan kerja merupakan faktor penting yang mempengaruhi kepuasan hidup pekerja, karena sebagian besar waktunya digunakan untuk bekerja. Dengan terpenuhinya kebutuhan kebutuhan tersebut maka para pegawai akan merasa dihargai keberadaannya. Hasil positif yang akan diperoleh adalah meningkatnya tingkat kinerja individual. Peningkatan kinerja individual tersebut akan mendorong pula peningkatan kinerja manajerial secara tidak langsung.

Kepuasan kerja tersebut akan didapat apabila ada kesesuaian antara harapan pekerja dengan kenyataan yang ditemui dan didapatkan dari tempatnya bekerja. Kepuasan kerja merupakan salah satu faktor yang sangat penting bagi individu dalam bekerja untuk mendapatkan hasil yang optimal. Kepuasan kerja merupakan penilaian pekerja yaitu seberapa jauh pekerjaannya secara keseluruhan memuaskan kebutuhannya. Kepuasan kerja pegawai pada dasarnya sangat individualistis dan merupakan hal yang sangat tergantung pada pribadi masingmasing karyawan. Namun demikian terdapat beberapa variabel yang berpengaruh terhadap kepuasan kerja pegawai, seperti komunikasi.

Di dalam organisasi pemerintah komunikasi merupakan salah satu kebutuhan dan aktivitas dasar manusia. Komunikasi dan manusia adalah dua hal yang sulit dipisahkan. Manusia di dalam kehidupannya harus berkomunikasi, artinya memerlukan orang lain dan membutuhkan kelompok atau masyarakat untuk saling berinteraksi. Interaksi yang dilakukannya melalui komunikasi, baik secara verbal maupun nonverbal, baik secara lisan maupun tulisan. Hal ini merupakan suatu hakekat bahwa sebagian besar pribadi manusia terbentuk dari hasil integrasi sosial dengan sesamanya.
Dalam kehidupannya manusia sering dipertemukan satu sama lainnya dalam suatu wadah baik formal maupun informal.

Komunikasi adalah merupakan bagian yang penting dalam kehidupan kerja suatu organisasi. Hal ini dapat dipahami, sebab komunikasi yang tidak baik mempunyai dampak yang luas terhadap kehidupan organisasi, seperti konflik antar karyawan, dan sebaliknya komunikasi yang efektif dapat meningkatkan saling pengertian, kerjasama, kepuasan kerja dan kinerja. Komunikasi mempunyai pengaruh yang positif dan signifikan terhadap kepuasan kerja pegawai. Komunikasi yang buruk paling sering disebut sebagai sumber konflik antar pribadi.

\section{Tujuan Penelitian}

Adapun yang menjadi tujuan dalam penelitian ini adalah:

1. Untuk mengetahui pengaruh komunikasi internal dan eksternal terhadap kepuasan kerja pegawai pada Dinas Pertanian dan Peternakan Kabupaten Pidie.

2. Untuk mengetahui variabel yang paling dominan berpengaruh terhadap kepuasan kerja pegawai pada Dinas Pertanian dan Peternakan Kabupaten Pidie.

\section{Tinjauan Pustaka}

\section{Pengertian Komunikasi}

Komunikasi (communication) adalah proses penyampaian pesan dalam bentuk lambang bermakna sebagai paduan pikiran dan perasaan berupa ide, informasi, kepercayaan, harapan, himbauan dan sebagainya, yang dilakukan seseorang kepada orang lain, baik langsung secara tatap muka maupun tak langsung melalui media, dengan tujuan mengubah sikap, pandangan atau perilaku. Kepuasan kerja adalah suatu tingkatan emosi yang menyenangkan dan bersifat positifyang muncul atau dihasilkan dari penilaian terhadap suatu prestasi kerja atau pengalaman (Luthans, 2006:65). 
Menurut Robbins (2006:392), memberi definisi komunikasi adalah proses penyampaian informasi, gagasan, pikiran dan ide dari satu orang kepada orang lain.

Sedangkan menurut Effendi (2006:5), komunikasi adalah proses penyampaian suatu pesan oleh seseorang kepada orang lain untuk memberi atau mengubah sikap, pendapat, atau perilaku, baik langsung secara lisan maupun tak langsung melalui media.

Dari pendapat diatas dapat disimpulkan bahwa komunikasi adalah penyampaian pesan dari satu orang kepada orang lain baik berupa informasi, gagasan pikiran dan ide baik secara langsung maupun tidak langsung yang nantinya akan mengubah sikap ataupun perilaku seseorang.

\section{Pengertian Kepuasan Kerja}

Kepuasan kerja dinikmati dalam pekerjaan, luar pekerjaan dan kombinasi dalam dan luar pekerjaan. Kepuasan kerja sebagai sikap secara umum dan tingkat perasaan positif seseorang terhadap pekerjaannya. (Robbins, 2006:103).

Karyawan yang mendapatkan kepuasaan kerja akan melaksanakan pekerjaan dengan lebih baik, karyawan yang tidak memperoleh kepuasan kerja tidak akan pernah mencapai kematangan psikologi yang akan menyebabkan frustasi. Karyawan seperti ini akan sering melamun, semangat kerja yang rendah, cepat bosan dan lelah, emosi tidak stabil, sering absen dan melakukan kesibukan yang tidak ada hubungannya dengan pekerjaan yang harus dilakukan (Hasibuan, 2007:200).

Sedangkan menurut Tangkilisan (2005:32), mengemukakan bahwa kepuasaan kerja (job satisfaction) adalah keadaan emosional yang menyenangkan atau tidak menyenangkan dari para karyawan dalam memandang pekerjaan mereka.

Dari pengertian diatas dapat disimpulkan bahwa kepuasan kerja adalah perasaan senang atau tidak senangnya dalam diri pegawai yang berhubungan dengan pekerjaan atau lingkungan kerjanya.

\section{Metode Penelitian Ruang Lingkup Penelitian}

Ruang Lingkup dalam penelitian ini adalah komunikasi yang berpengaruh terhadap kepuasan kerja pegawai pada Dinas Pertanian dan Peternakan Kabupaten Pidie.

\section{Lokasi dan Objek Penelitian}

Lokasi penelitian ini dilakukan di Dinas Pertanian dan Peternakan Kabupaten Pidie. Objek dalam penelitian ini yang berhubungan dengan komunikasi yang berpengaruh terhadap kepuasan kerja pegawai pada Dinas Pertanian dan Peternakan Kabupaten Pidie.

\section{Populasi dan Sampel \\ Populasi}

Populasi adalah keseluruhan objek penelitian (Arikunto, 2006:130). Jadi populasi dalam penelitian ini adalah seluruh pegawai yang bekerja pada Dinas Pertanian dan Peternakan Kabupaten Pidie, yaitu berjumlah 35 orang pegawai

\section{Sampel}

Menurut Arikunto, (2006:134), jumlah sampel yang akan diambil, adalah apabila subjek kurang dari 100 orang, lebih baik diambil semua, akan tetapi jika jumlah subjeknya besar maka jumlah sampel yang akan diambil adalah antara $10-15 \%$ atau 2025\% (Arikunto 2006:134). Jadi jumlah sampel yang diambil adalah seluruh populasi yang ada dikantor tersebut sejumlah 35 orang pegawai.

\section{Teknik Pengumpulan Data}

a. Kuesioner, yaitu pengumpulan data yang dilakukan oleh penulis dengan cara menyebarkan daftar pernyataan yang telah di format khusus kepada responden yang sifatnya tertutup, yang pilihan 
jawabannya dengan menggunakan skala likert (1-5).

b. Wawancara, yaitu pengumpulan data yang dilakukan oleh penulis dengan cara melakukan tanya jawab secara langsung dengan pihak-pihak yang bersangkutan guna mendapatkan data dan informasi untuk mendukung penelitian ini.

c. Studi pustaka, yaitu pengumpulan data yang dilakukan oleh penulis dengan mengumpulkan data yang bersumber dari literatur-literatur, bahan kuliah, dan hasil penelitian lainnya yang ada hubungannya dengan objek penelitian.

\section{Skala Pengukuran}

Skala pengukuran yang di gunakan adalah skala likert (Liker scale). Skala likert pada dasarnya adalah skala ordinal karena menunjukan tingkat data. Skala likert yang digunakan dalam penelitian ini adalah skala lima poin berkisar 1 sampai 5. Pemberian skala untuk memberikan bobot atau skor terhadap masing-masing tingkat kesetujuan sebagai alternatif pilihan jawaban pada masing-masing pernyataan, seperti terlihat dalam Table III-1 berikut.

Alternatif pilihan jawaban kuesioner berdasarkan skor

\begin{tabular}{|c|c|c|}
\hline Pilihan & Keterangan & Score \\
\hline STS & Sangat Tidak Setuju & 1 \\
\hline TS & Tidak Setuju & 2 \\
\hline KS & Kurang Setuju & 3 \\
\hline S & Setuju & 4 \\
\hline SS & Sangat Setuju & 5 \\
\hline
\end{tabular}

\section{Peralatan Analisis Data}

Metode analisis data yang digunakan dalam penelitian ini adalah Regresi Berganda yang diolah melalui komputer dengan menggunakan program SPSS. Regresi linear berganda dapat dirumuskan secara berikut (Sugiyono, 2009:21) :
$\mathrm{Y}=\alpha+\mathrm{b}_{1} \mathrm{X}_{1}+\mathrm{b}_{2} \mathrm{X}_{2}+\mathrm{e}$

Dimana:

$\mathrm{Y}=$ Loyalitas Konsumen

$\alpha=$ Konstanta

$\mathrm{b}_{1}=$ Koefisien regresi komunikasi internal

$b_{2}=$ Koefisien regresi komunikasi eksternal

$\mathrm{X}_{1}=$ Variabel komunikasi internal $\left(\mathrm{X}_{1}\right)$

$\mathrm{X}_{2}=$ Variabel komunikasi eksternal $\left(\mathrm{X}_{2}\right)$

$\mathrm{e}=$ error

\section{Hasil Penelitian Dan Pembahasan Uji Reliabilitas}

Uji reliabilitas kuisioner dinilai dengan menggunakan croanbach alpha. Croanbach alpha menerjemahkan kolerasi antara skala yang dirancang dengan seluruh skala yang diukur, dan juga dapat mengukur objek yang sama. Tingkat koefisien yang dinyatakan handal sebesar 0,60, sedangkan reliabilitas dibawah tersebut dianggap kurang reliabel.

\begin{tabular}{|c|c|c|c|}
\hline Nama Variabel & $\begin{array}{l}\text { Cronb } \\
\text { ach } \\
\text { Alpha }\end{array}$ & $\begin{array}{c}\text { Jumlah } \\
\text { Indikato } \\
\mathbf{r} \\
\text { Variabel }\end{array}$ & $\begin{array}{c}\text { Keteran } \\
\text { gan }\end{array}$ \\
\hline $\begin{array}{l}\text { Komunikasi } \\
\text { Internal }\left(\mathrm{X}_{1}\right)\end{array}$ & 0.758 & 4 & Handal \\
\hline $\begin{array}{l}\text { Komunikasi } \\
\text { Eksternal }\left(\mathrm{X}_{2}\right)\end{array}$ & 0.824 & 4 & Handal \\
\hline $\begin{array}{l}\text { Kepuasan Kerja } \\
\text { (Y) }\end{array}$ & 0.845 & 6 & Handal \\
\hline
\end{tabular}

Sumber : Data Primer Penelitian (Diolah), 2018

Dari tabel IV.3 semua indikator pertanyaan masing - masing variabel baik variabel independen yaitu komunikasi internal $\left(\mathrm{X}_{1}\right)$, dan variabel komunikasi eksternal $\left(\mathrm{X}_{2}\right)$ maupun variabel independen yaitu variabel kepuasan kerja (Y) dapat dikatakan handal karena nilai Cronbach Alpha lebih besar dari 0,60

\section{Uji Validitas}

Penentuan validitas didasarkan atas perbandingan nilai kolerasi (r) yang diperoleh antara skor item dengan skor total 
item, dengan nilai kritis kolerasi produck moment. Apabila nilai kolerasi dihitung lebih besar bila dibandingkan dengan nilai produck moment pada tingkat keyakinan $95 \%$ dapat dinyatakan item-item pertanyaan tersebut valid, ataupun dengan melihat hasil $\mathrm{r}_{\text {hitung }}>$ $r_{\text {tabel }}$ dinyatakan valid dan sebaliknya hasil $r$ hitung $<\mathrm{r}_{\text {tabel }}$ dinyatakan tidak valid. Hasil perhitungan dengan menggunakan SPSS 0.17 adalah sebagai berikut :

\section{Tabel IV.2}

\section{Hasil Uji Validitas}

\begin{tabular}{|c|c|c|c|}
\hline Variabel & $\mathbf{r}_{\text {hitung }}$ & $\begin{array}{c}\mathbf{r}_{\text {tabel }} \\
(\mathbf{N}=\mathbf{3 5})\end{array}$ & Keterangan \\
\hline $\begin{array}{l}\text { Komunikasi } \\
\text { Internal } \\
\left(\mathrm{X}_{1}\right)\end{array}$ & $\begin{array}{l}0,832 \\
0,710 \\
0,817 \\
0,701\end{array}$ & $\begin{array}{l}0,334 \\
0,334 \\
0,334 \\
0,334\end{array}$ & $\begin{array}{l}\text { Valid } \\
\text { Valid } \\
\text { Valid } \\
\text { Valid }\end{array}$ \\
\hline $\begin{array}{l}\text { Komunikasi } \\
\text { Eksternal } \\
\left(\mathrm{X}_{2}\right)\end{array}$ & $\begin{array}{l}0,814 \\
0,822 \\
0,762 \\
0,843\end{array}$ & $\begin{array}{l}0,334 \\
0,334 \\
0,334 \\
0,334\end{array}$ & $\begin{array}{l}\text { Valid } \\
\text { Valid } \\
\text { Valid }\end{array}$ \\
\hline $\begin{array}{c}\text { Kepuasan } \\
\text { Kerja } \\
\text { (Y) }\end{array}$ & $\begin{array}{l}0,714 \\
0,721 \\
0,764 \\
0,772 \\
0,795 \\
0,749\end{array}$ & $\begin{array}{l}0,334 \\
0,334 \\
0,334 \\
0,334 \\
0,334 \\
0,334\end{array}$ & $\begin{array}{l}\text { Valid } \\
\text { Valid } \\
\text { Valid } \\
\text { Valid } \\
\text { Valid } \\
\text { Valid }\end{array}$ \\
\hline
\end{tabular}

Sumber : Data Primer Penelitian (Diolah) , 2018

Dari tabel IV-2 di atas dapat disimpulkan bahwa semua indikator pertanyaan masing - masing variabel baik variabel independen yaitu komunikasi internal $\left(X_{1}\right)$, dan variabel komunikasi eksternal $\left(\mathrm{X}_{2}\right)$ maupun variabel independen yaitu variabel kepuasan kerja (Y) dinyatakan valid, karena semuanya memperoleh nilai $\mathrm{r}_{\text {hitung }}<\mathrm{r}_{\text {tabel }}$.

\section{Uji Normalitas}

Residual variabel yang terdistribusi normal akan terletak disekitar garis horizontal (tidak terpisah jauh dari garis diagonal), dan data normal jika garis yang menggambarkan data sesungguhnya akan mengikuti garis diagonalnya. Hasil olahan data diperoleh adalah sebagai sebagai berikut

\section{Gambar IV.1 Grafik Uji Normalitas}

Normal P-P Plot of Regression Standardized
Residual

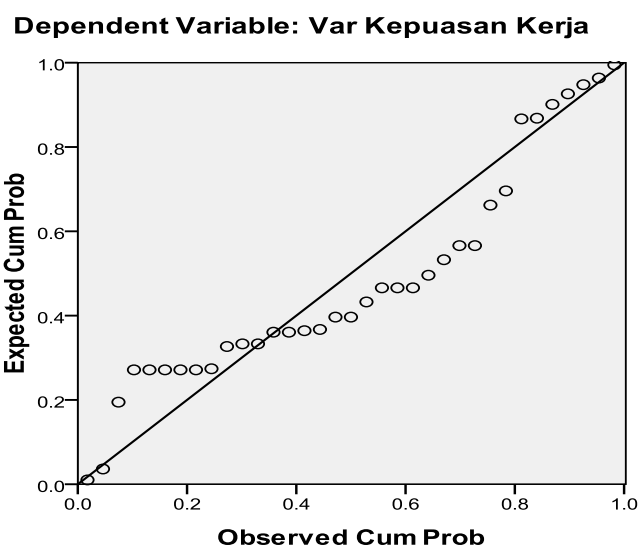

Dari gambar IV.1 di atas dapat disimpulkan bahwa grafik tersebut berdistribusi normal karena terletak disekitar garis (tidak terpisah jauh dari garis diagonal), dan data normal jika garis yang menggambarkan data sesungguhnya akan mengikuti garis diagonalnya.

\section{Uji Multikolinearitas}

Untuk mendeteksi ada atau tidaknya multikolinearitas di dalam model regresi adalah mempunyai nilai VIF di bawah atau kurang dari nilai $10(<10)$. Hasil pengolahan data sebagai berikut :

Nilai VIF

\begin{tabular}{|c|l|c|c|}
\hline $\begin{array}{c}\text { N } \\
\mathbf{o}\end{array}$ & \multicolumn{1}{|c|}{$\begin{array}{c}\text { Nama } \\
\text { Variabel }\end{array}$} & $\begin{array}{c}\text { Nilai } \\
\text { VIF }\end{array}$ & Keterangan \\
\hline 1 & $\begin{array}{l}\text { Komunikasi } \\
\text { Internal }\left(\mathrm{X}_{1}\right)\end{array}$ & 4.079 & $\begin{array}{c}\text { Non } \\
\text { Multikolinearitas }\end{array}$ \\
\hline 2 & $\begin{array}{l}\text { Komunikasi } \\
\text { Eksternal }\left(\mathrm{X}_{2}\right)\end{array}$ & 4.079 & $\begin{array}{c}\text { Non } \\
\text { Multikolinearitas }\end{array}$ \\
\hline
\end{tabular}

Sumber : Data Primer Penelitian (Diolah), 2016 
Dari tabel di atas dapat di simpulkan bahwa tidak ada multikolinieritas karena mempunyai nilai VIF di bawah atau kurang dari nilai $10(<10)$.

\section{Uji Hesterokedestisitas}

Deteksi ada tidaknya heteroskedastisitas dapat dilakukan dengan melihat ada tidaknya pola tertentu pada grafik scatter plot. Jika ada pola tertentu, seperti titik-titik yang ada membentuk pola tertentu yang teratur (bergelombang, melebar kemudian menyempit), maka telah terjadi heteroskedastisitas. Jika tidak ada pola yang jelas, maka tidak terjadi heteroskedastisitas. Hasil olahan data sebagai berikut :

\section{Grafik Uji Heterokedastisitas}

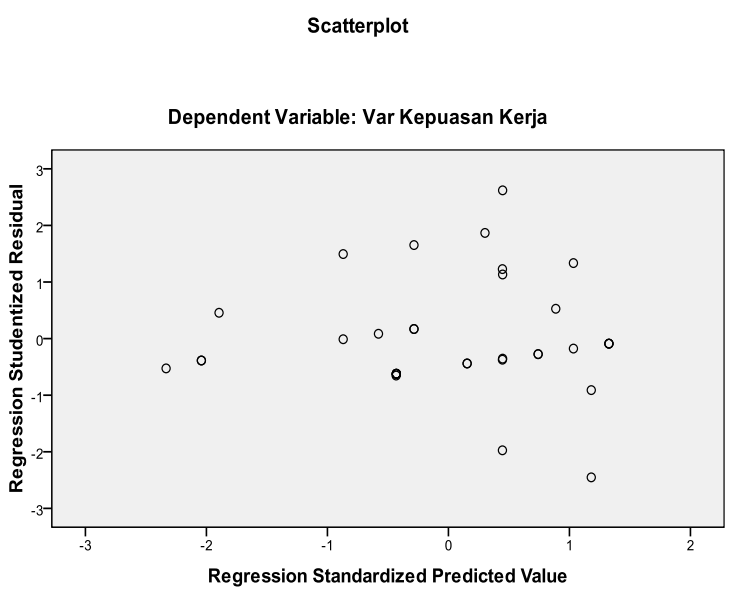

Dari gambar IV.2 diatas dapat disimpulkan bahwa tidak adanya heteroskedastisitas pada grafik tersebut karena tidak adanya ada pola tertentu, seperti titik-titik yang ada membentuk pola tertentu yang teratur (bergelombang, melebar kemudian menyempit).

\section{Hasil Regresi Linear Berganda}

Untuk melihat sejauh mana pengaruh variabel komunikasi internal $\left(\mathrm{X}_{1}\right)$ dan variabel komunikasi eksternal $\left(\mathrm{X}_{2}\right)$ terhadap kepuasan kerja (Y) perlu dilakukan perhitungan regresi berganda, dimana hasil perhitungan akhirnya adalah sebagai berikut:

\section{Hasil Analisis Regresi Linier Berganda}

\begin{tabular}{|c|c|c|c|c|c|c|}
\hline \multirow[t]{2}{*}{ Model } & \multicolumn{2}{|c|}{$\begin{array}{l}\text { Unstandardi } \\
\text { zed } \\
\text { Coefficients }\end{array}$} & \multirow{2}{*}{\begin{tabular}{|c|}
$\begin{array}{c}\text { Standardi } \\
\text { zed } \\
\text { Coefficient } \\
\text { s }\end{array}$ \\
Beta
\end{tabular}} & \multirow[t]{2}{*}{$\mathbf{t}_{\text {hitung }}$} & \multirow[t]{2}{*}{$\begin{array}{c}\mathbf{t}_{\text {tab }} \\
\text { el }\end{array}$} & \multirow[t]{2}{*}{ Sig. } \\
\hline & B & $\begin{array}{l}\text { Std. } \\
\text { Error }\end{array}$ & & & & \\
\hline $1\left(\begin{array}{l}\text { (Consta } \\
\text { nt) }\end{array}\right.$ & $\begin{array}{l}1.8 \\
53\end{array}$ & .907 & & $\begin{array}{c}2.04 \\
3\end{array}$ & $\begin{array}{c}2.0 \\
36 \\
9\end{array}$ & .049 \\
\hline $\begin{array}{l}\text { Var } \\
\text { Komuni } \\
\text { kasi } \\
\text { Internal }\end{array}$ & $\begin{array}{c}94 \\
2\end{array}$ & .100 & .682 & $\begin{array}{c}9.41 \\
1\end{array}$ & $\begin{array}{c}2.0 \\
36 \\
9\end{array}$ & .000 \\
\hline \begin{tabular}{|l} 
Var \\
Komuni \\
kasi \\
Ekstern \\
al
\end{tabular} & $\begin{array}{c}.46 \\
8\end{array}$ & .104 & .327 & $\begin{array}{c}4.50 \\
8\end{array}$ & $\begin{array}{c}2.0 \\
36 \\
9\end{array}$ & .000 \\
\hline
\end{tabular}

Sumber : Data Primer Penelitian (Diolah), 2018

Dari tabel IV.8 diatas yaitu hasil regresi linear berganda dapat di jelaskan sebagai berikut:

$$
\mathrm{Y}=1,853+0,942 \mathrm{X}_{1}+0,468 \mathrm{X}_{2}
$$

Dari persamaan regresi linear berganda di atas, dapat diartikan nilai dari masingmasing koefisien, yaitu:

Konstanta $(\alpha)$ diperoleh nilai sebesar 1,853 yang berarti bahwa jika tingkat komunikasi internal $\left(\mathrm{X}_{1}\right)$ dan komunikasi eksternal $\left(\mathrm{X}_{2}\right)$ dianggap konstan, maka kepuasan kerja pegawai pada Dinas Pertanian dan Peternakan Kabupaten Pidie adalah sebesar 1,853. Ini berarti bahwa nilai yang diperoleh masih pada satuan skala likert dianggap sangat rendah.

Selanjutnya koefisien variabel komunikasi internal $\left(\mathrm{X}_{1}\right)$ diperoleh nilai sebesar 0,942, yang berarti bahwa setiap kenaikan komunikasi internal $1 \%$, maka kepuasan kerja pegawai pada Dinas Pertanian dan Peternakan Kabupaten Pidie adalah 
sebesar 0,942. Sedangkan koefisien variabel komunikasi eksternal $\left(\mathrm{X}_{2}\right)$ diperoleh nilai sebesar 0,468, yang berarti bahwa setiap kenaikan komunikasi eksternal 1\%, maka kepuasan kerja pegawai pada Dinas Pertanian dan Peternakan Kabupaten Pidie adalah sebesar 0,468 .

Dari hasil pengujian diatas terlihat bahwa variabel yang dominan berpengaruh terhadap kepuasan kerja pegawai pada Dinas Pertanian dan Peternakan Kabupaten Pidie adalah variabel komunikasi internal $\left(\mathrm{X}_{1}\right)$ dengan nilai yang diperoleh adalah sebesar 0,942 .

\section{Uji Kolerasi dan Determinasi}

Untuk melihat besarnya pengaruh dan hubungan dari masing-masing variabel independen terhadap variabel dependen, maka dapat dilihat pada tabel berikut ini :

\begin{tabular}{|c|c|c|c|c|c|c|c|c|c|c|}
\hline \multirow[b]{2}{*}{ Model } & \multirow[b]{2}{*}{ R } & \multirow[b]{2}{*}{$\begin{array}{c}\mathrm{R} \\
\text { Square }\end{array}$} & \multirow{2}{*}{$\begin{array}{c}\text { Adjusted } \\
\mathrm{R} \\
\text { Square }\end{array}$} & \multirow{2}{*}{$\begin{array}{l}\text { Sid. } \\
\text { Enor of } \\
\text { the } \\
\text { Estimate }\end{array}$} & \multicolumn{5}{|c|}{ Change Statistics } & \multirow[b]{2}{*}{$\begin{array}{l}\text { Dublin } \\
\text { Watsen }\end{array}$} \\
\hline & & & & & $\begin{array}{c}\mathrm{R} \\
\text { Square } \\
\text { Clange }\end{array}$ & $\begin{array}{c}\mathrm{F} \\
\text { Change }\end{array}$ & dfI & $\mathrm{d} \mathscr{L}$ & $\begin{array}{c}\text { Sig. } \mathrm{F} \\
\text { Clange }\end{array}$ & \\
\hline 1 & 9791 & 959 & .956 & .68597 & 959 & 372.472 & 2 & 32 & .000 & 2.079 \\
\hline
\end{tabular}

Sumber : Data Primer Penelitian (Diolah), 2018

Dari tabel di atas dapat dijelaskan besarnya pengaruh dan hubungan variabel independen terhadap variabel dependen sebagai berikut:

Besarnya hubungan antara variabel komunikasi internal $\left(\mathrm{X}_{1}\right)$, dan komunikasi eksternal $\left(\mathrm{X}_{2}\right)$ terhadap kepuasan kerja pegawai pada pada Dinas Pertanian dan Peternakan Kabupaten Pidie yaitu sebesar 97,9\% yang ditunjukkan oleh koefisien korelasi (R) sebesar 0,979. Ini berarti hubungan sangat erat, karena memiliki koefisien korelasi (R) lebih besar dari 90\%.

Sedangkan besarnya pengaruh antara variabel komunikasi internal $\left(\mathrm{X}_{1}\right)$, dan komunikasi eksternal $\left(\mathrm{X}_{2}\right)$ secara bersamasama berpengaruh secara signifikan terhadap kepuasan kerja pegawai pada Dinas Pertanian dan Peternakan Kabupaten Pidie 95,9\%, seperti ditunjukkan oleh koefisien determinasi $\left(\mathrm{R}^{2}\right)$ sebesar 0,959. Hanya sebesar $4,1 \%$ yang dipengaruhi oleh variabel lain yang tidak diteliti dalam penelitian.

\section{Pembuktian Hipotesis}

\section{Pembuktian Secara Simultan (Uji F)}

Uji $F$ (F test): untuk menguji pengaruh secara simultan dari variabel bebas terhadap variabel terikat.

- Jika $\mathrm{F}$ hitung > F tabel : menerima Ha, menolak Ho

- Jika F hitung < F tabel : menolak Ha, menerima Ho

Hasil pengolahan data terlihat pada tabel IV.10 berikut ini:

\section{Tabel IV.10 Hasil Uji F}

\begin{tabular}{|c|c|c|c|c|c|c|c|}
\hline & Model & $\begin{array}{l}\text { Sum of } \\
\text { Squares }\end{array}$ & DH & $\begin{array}{l}\text { Mean } \\
\text { Square }\end{array}$ & $r$ & Fiatel & Sig. \\
\hline \multirow[t]{3}{*}{1} & Regression & 350.542 & 2 & 175.271 & 372.472 & 3.2945 & .000 \\
\hline & Residual & 15.058 & 32 & 471 & & & \\
\hline & Total & 365.600 & 34 & & & & \\
\hline
\end{tabular}

Dari tabel IV.10 di atas dapat di disimpulkan bahwa secara simultan di peroleh $F_{\text {hitung }} 372,427>F_{\text {tabel }} 3,2945$. Dengan demikian, menerima hipotesis alternatif (Ha) dan menolak hipotesis nol (Ho), artinya bahwa variabel komunikasi internal $\left(\mathrm{X}_{1}\right)$, dan komunikasi eksternal $\left(\mathrm{X}_{2}\right)$, secara bersama-sama berpengaruh secara signifikan terhadap kepuasan kerja pegawai pada pada Dinas Pertanian dan Peternakan Kabupaten Pidie.

\section{Pembuktian Secara Parsial (Uji t)}

Uji t (t test) : untuk menguji pengaruh secara parsial variabel bebas terhadap variabel terikat.

- Jika t hitung > t tabel : menerima Ha, menolak Ho

- Jika t hitung < t tabel : menolak Ha, menerima Ho 
- Hasil pengolahan data terlihat pada tabel IV.11 berikut ini:

\section{Hasil Uji t}

\begin{tabular}{|c|c|c|c|c|c|c|c|}
\hline \multirow{2}{*}{\multicolumn{2}{|c|}{ Model }} & \multicolumn{2}{|c|}{$\begin{array}{l}\text { Unstanilardized } \\
\text { Coefficients }\end{array}$} & \multirow{2}{*}{\begin{tabular}{|c|}
$\begin{array}{c}\text { Standardized } \\
\text { Coefficients }\end{array}$ \\
Beta \\
\end{tabular}} & \multirow{2}{*}{$t_{\text {bituag }}$} & \multirow{2}{*}{$t_{\text {tabel }}$} & \multirow{2}{*}{ Sig. } \\
\hline & & B & $\begin{array}{c}\text { Stcl. } \\
\text { Error }\end{array}$ & & & & \\
\hline \multirow[t]{3}{*}{1} & (Constant) & 1.853 & .907 & & 2.043 & 2.0369 & .049 \\
\hline & $\begin{array}{l}\text { Var Kommikasi } \\
\text { Internal }\end{array}$ & .942 & .100 & .682 & 9.411 & 2.0369 & .000 \\
\hline & $\begin{array}{l}\text { Var Kommikasi } \\
\text { Eksternal }\end{array}$ & .468 & .104 & .327 & 4.508 & 2.0369 & .000 \\
\hline
\end{tabular}

Variabel komunikasi internal $\left(\mathrm{X}_{1}\right)$, diperoleh $t_{\text {hitung }} 9,411>t_{\text {tabel }}$ 2,0369. Maka $\mathrm{H}_{\mathrm{a}}$ diterima dan $\mathrm{H}_{0}$ ditolak. Jadi dapat disimpulkan bahwa variabel komunikasi internal $\left(\mathrm{X}_{1}\right)$, memberikan pengaruh yang signifikan terhadap kepuasan kerja pegawai pada Dinas Pertanian dan Peternakan Kabupaten Pidie.

Sedangkan variabel komunikasi eksternal $\left(\mathrm{X}_{2}\right)$, diperoleh $\mathrm{t}_{\text {hitung }} 4,508>\mathrm{t}_{\text {tabel }}$ 2,0369. Maka $\mathrm{H}_{\mathrm{a}}$ diterima dan $\mathrm{H}_{0}$ ditolak. Jadi dapat disimpulkan bahwa variabel komunikasi eksternal $\left(\mathrm{X}_{2}\right)$, memberikan pengaruh yang signifikan terhadap kepuasan kerja pegawai pada Dinas Pertanian dan Peternakan Kabupaten Pidie.

\section{Kesimpulan}

1. Besarnya hubungan antara variabel komunikasi internal $\left(\mathrm{X}_{1}\right)$, dan komunikasi eksternal $\left(\mathrm{X}_{2}\right)$ terhadap kepuasan kerja pegawai pada pada Dinas Pertanian dan Peternakan Kabupaten Pidie yaitu sebesar $97,9 \%$ yang ditunjukkan oleh koefisien korelasi (R) sebesar 0,979. Ini berarti hubungan sangat erat, karena memiliki koefisien korelasi (R) lebih besar dari $90 \%$.

2. Besarnya pengaruh antara variabel komunikasi internal $\left(\mathrm{X}_{1}\right)$, dan komunikasi eksternal $\left(\mathrm{X}_{2}\right)$ secara bersama-sama berpengaruh secara signifikan terhadap kepuasan kerja pegawai pada Dinas Pertanian dan Peternakan Kabupaten Pidie 95,9\%, seperti ditunjukkan oleh koefisien determinasi $\left(\mathrm{R}^{2}\right)$ sebesar 0,959. Hanya sebesar $4,1 \%$ yang dipengaruhi oleh variabel lain yang tidak diteliti dalam penelitian.

3. Secara simultan dapat di disimpulkan bahwa secara simultan di peroleh $F_{\text {hitung }}$ 372,427 > $F_{\text {tabel 3,2945. Dengan }}$ demikian, menerima hipotesis alternatif (Ha) dan menolak hipotesis nol (Ho), artinya bahwa variabel komunikasi internal $\left(\mathrm{X}_{1}\right)$, dan komunikasi eksternal $\left(\mathrm{X}_{2}\right)$, secara bersama-sama berpengaruh secara signifikan terhadap kepuasan kerja pegawai pada pada Dinas Pertanian dan Peternakan Kabupaten Pidie.

4. Secara parsial dapat disimpulkan sebagai berikut :Variabel komunikasi internal $\left(\mathrm{X}_{1}\right)$, diperoleh $\mathrm{t}_{\text {hitung }} 9,411>\mathrm{t}_{\text {tabel }} 2,0369$. Maka $\mathrm{H}_{\mathrm{a}}$ diterima dan $\mathrm{H}_{0}$ ditolak. Jadi dapat disimpulkan bahwa variabel komunikasi internal $\left(\mathrm{X}_{1}\right)$, memberikan pengaruh yang signifikan terhadap kepuasan kerja pegawai pada Dinas Pertanian dan Peternakan Kabupaten Pidie. Sedangkan variabel komunikasi eksternal $\left(\mathrm{X}_{2}\right)$, diperoleh $\mathrm{t}_{\text {hitung }}$ 4,508 > $\mathrm{t}_{\text {tabel }}$ 2,0369. Maka $\mathrm{H}_{\mathrm{a}}$ diterima dan $\mathrm{H}_{0}$ ditolak. Jadi dapat disimpulkan bahwa variabel komunikasi eksternal $\left(\mathrm{X}_{2}\right)$, memberikan pengaruh yang signifikan terhadap kepuasan kerja pegawai pada Dinas Pertanian dan Peternakan Kabupaten Pidie.

\section{Daftar Pustaka}

Effendi, H. 2006. Telah Kualitas Air Bagi Pengelola Dan Sumber Daya Lingkungan Perairan. Cetakan Kelima. Yogyakarta : Kanisius.

Ghozali, Imam. 2005. Aplikasi Analis Multivariate dengan program IBM SPSS 19. Semarang : Universitas diPonegoro. 
Hasibuan , M.S.P. 2007. Manajemen Sumber Daya Manusia. Jakarta : Bumi Aksara.

Hicks, Herbert G dan Gullet G Ray. 2009. Organisasi Teori dan Tingkah Laku. Jakarta: Bumi Aksara

Hidayat, Rachmad. 2012. Pengaruh Kepemimpinan Komunikasi Kepuasan Kerja Terhadap Komitmen Organisasi Pada Industri Perbankan. Madura: Fakultas Ekonomi Madura.

Husen, Umar. 2005. Riset Manajemen Sumber Daya Manusia Dalam Organisasi. Jakarta : Gramedia Pustaka Utama.

Luthans. Fred. 2006. Perilaku Organisasi. Yogyakarta: Penerbit Andi Yogyakarta.

Mustika. 2014. Analisis Pengaruh Komunikasi Organisasi dan Komitmen Keoranisasian Terhadap Kepuasan Kerja Karyawan PT. BTPN Tbk Kcp Pasar Baru Merangin.Semarang: Gakultas Ekonomi Semarang.

Robbins, Stephen. P. 2006. Perilaku Organisasi (Alih Bahasa Drs. Benjamin Molan), Edisi Bahasa
Indonesia, Klaten: PT INTAN SEJATI.

Rivai, V. 2005. Manajemen Sumber Daya Manusia Untuk Perusahaan Dari Teori Kepraktik. Jakarta : PT. Raja Grafindo Persada.

Sinambela, Lijan Poltak, dkk. 2012. Kinerja Pegawai Teori Pengukuran Dan Implikasi. Yogyakarta: Graha Ilmu.

Sugiyono. 2009. Metode Penelitian Kuantitatif dan $R \& D$. Bandung: Alfabeta

Suharsimi, Arikunto. 2006. Prosedur Penelitian. Jakarta: Rineka Cipta

Suranto, AW. 2005. Komunikasi Perkantoran, Edisi 1. Yogyakrta: Media Wacana

Tangkilisan, Hessel Nogi S. 2005. Manajemen Publik. Jakarta: Gramedia Widia Sarana Indonesia

Utami, Fitri Cinta. 2012. Pengaruh Kepemimpinan, Komunikasi, Disiplin Kerja Terhadap Kinerja Karyawan (Studi Kasus Pada Kantor BAPPEDA Kabupaten Sukoharjo). Surakarta: Fakultas Ekonomi Surakarta 